\title{
FISCAL CONSOLIDATION IN GENERAL EQUILIBRIUM FRA- MEWORK (the case of the Czech Republic)
}

\author{
Jaromír HURNÍK*
}

\begin{abstract}
:
Within the non-stochastic dynamic general equilibrium model framework this paper examines the implications of alternative fiscal consolidation programs for small open economy. The calibrated model enables realistically quantify the impact of the deficit financing and fiscal consolidation on consumption and saving of households, investment of firms and thereby on the capital stock and real interest rates. Through the interest rate link the impact of deficit financing and fiscal consolidation on cyclical and long-term properties of monetary policy set-up can be observed. Several fiscal consolidations were simulated in order to demonstrate the comparative statics and differences in dynamic paths of above mentioned variables.
\end{abstract}

Keywords: fiscal consolidation, general equilibrium model

JEL Classification: E10, E62, H30

\section{Introduction}

The end of the twentieth century could be characterised as a period of fiscal consolidations. During that period many countries underwent the fiscal adjustment procedure in order to stabilize their fiscal sector. The need of fiscal consolidation was a consequence of the deficit bias of public finance in the post world war period (see Kopits, 2002). During that period the level of public debt had increased dramatically.

The need of fiscal consolidation has raised broad discussion about consequences of particular fiscal consolidations. The main interest has been focused on the

*) Czech National Bank, Na Př́íkopě 28, CZ - 11503 Prague 1 and University of Economics, 4, W. Churchill Sq., 13067 Prague 3 (e-mail: jaromir.hurnik@ cnb.cz).

${ }^{* *}$ ) In December 2003, the Czech Economic Association announced the results of the "Young Economist of 2003" and "Engliš Prize" contest. Now, we are publishing the scientific study, which was awarded the Engliš Prize (note of the editor).

$\left.{ }^{\star * *}\right)$ First draft of this paper was written for the $59^{\text {th }}$ Congress of the International Institute of Public Finance in Prague, 2003. I wish to thank to Jaromír Beneš for helpful comments concerning the linearization of the model around the steady state and to Vladimír Bezděk and Aleš Krejdl for helpful comments concerning the calibration of the model. Any opinions expressed are those of the author and not those of the Czech National Bank or University of Economics. 
short and long run impacts on the real output movements. According to the competing theories, the possible results differ substantially. Alesina and Perotti (1996) provide both, theoretical and practical survey in this area.

One possible way to estimate the transitory and ultimate effects of the particular consolidation is to use the dynamic general equilibrium model of the economy. Such a model is based on optimal behaviour of households and firms and contains also several different fiscal rules describing simply the fiscal authority behaviour. Introducing the government into the model and using several different types of fiscal rules makes it possible to provide a set of distinguish simulations. These model simulations then also enable to evaluate the simultaneous responses of the economy on the fiscal adjustment procedure.

Since the Czech government has recently announced the fiscal consolidation, the relevant arising question is the possible impact of different types of consolidation on the behaviour of households, firms and finally the economy as a whole in the Czech case. In order to provide such an analysis, first it is necessary to build the dynamic general equilibrium model that is, at least roughly, in accordance with the Czech reality.

Alesina and Perotti distinguish in general between two types of fiscal consolidations. The first one is labelled as successful one and is characterised by higher weight put on the reduction of the expenditure side of public budgets. The second one, in opposite labelled as unsuccessful one, is then characterised by higher weight put on revenue side of public budgets. To show the differences in reactions of the economy to the fiscal consolidation and to make things as simple as possible we simulate two basic fiscal consolidation scenarios. In both the government decided to decrease the government debt to output ratio with the ultimate target $10 \%$, but in one of them the fiscal consolidation is based entirely on the changes of value added $\operatorname{tax}^{1}$ ) while in the other on changes of government transfers and government consumption.

Next to these two basic simulations we present another one that is also based on changes in value added tax, but is simulated using forward-looking fiscal rule. This kind of simulation is inspired by the common use of forward-looking rules for description of monetary authority behaviour in dynamic general equilibrium models. The results show that when the government is more forward looking the use of value added taxes in order to consolidate the fiscal sector is less distortionary.

The fiscal consolidation has in practice impact on both the long run movements of the economy as well as on the dynamic paths around the steady state. Following this division we describe first the comparative statics, i.e. the differences among ultimate steady states, and then the differences in dynamic paths around the steady states.

The knowledge of the likely impacts of fiscal consolidation on the economy is important also for the central bank. The importance arises not only through the implied changes in the short run dynamics of the economy, but mainly through the changes in the steady state properties. As Alesina and Peroti showed, different types of fiscal consolidations have consequently different impact on the long run behaviour of the particular variables.

Our simulations of course represent very extreme examples of fiscal consolidations. However, the comparison of simulated results with empirical results and help of other expert knowledge should enable us to improve the model properties and

1) The value added tax was chosen as more plausible example in comparison to consolidation using income taxes. It is of course possible to prepare also such a simulation. 
later simulate the effects of more realistic fiscal consolidation scenarios. Let's bear in mind that this paper represents the very first draft of the model and its simulations.

This paper is organised as follows. Section 2 describes the structure of the used model. Section 3 then presents simulations of fiscal consolidation under different conditions and provides the comparison of their ultimate steady states and transitory dynamics. Section 4 discusses the implications of fiscal consolidation programs for monetary policy and the last section concludes.

\section{The Model}

This section provides a shortcut to the behavioral structure of the model and to the derivation of its first-order conditions. The model itself falls into the discrete-time perpetual-youth (see Blanchard, 1985; Yaari, 1965) strand of OLG models of twogood small open economies without money. Similar but not so complex model was used by Sutherland (1995). This framework constraints Ricardian properties of the model even with non-distortionary taxes and transfers. Evans (1991) showed in the simple Blanchard perpetual-youth model, without any life-cycle features, that the departures from Ricardian equivalence are quite small. So, in addition we introduce, following Faruqee and Laxton (2000), the life-cycle features using the age-earning profile for households wages revenues.

The home small open economy consists of five types of agents, households, producers of tradable goods, producers of non-tradable goods, capital rental firms, and the government. A generation of households is born at each period. Each household faces a constant non-zero probability of death. During their life households consume a variety of a large number of differentiated tradables and non-tradables, supply labor, and accumulate wealth. The wealth of died households is redistributed through a competitive insurance market to those alive; as a consequence the rate of growth of the individual wealth exceeds the aggregate one. Producers operate under monopolistic competition with each of them possessing one brandmark. Those of tradable goods sector use a two-factor (labor, capital) production technology; they demand labor, rent physical capital and supply they brandmarked production. Producers of non-tradables use a one-factor (labor based) technology so that they only demand labor and sell their production. No sector-specific labor skills are required and the labor supply is homogenous, however, we impose the indivisiblelabor restriction. Capital rental firms turn at zero cost tradable goods into physical capital and rent it to producers; the capital rental market is assumed competitive. In the behavioral background we assume two kinds of sluggishness to generate more realistic transitory dynamics, namely habit formation in households' consumption and capital installation cost.

The government levies three types of taxes: on labour income, corporate profit, and value added tax. These receipts are then used for government consumption of non-tradables and for tranfers to households. The government finance is balanced through its savings or debt that are perfect substitutes to those private ones. The country as a whole faces a risk premium over the world interest rate that is endogenously driven by the aggregate country indebtedness measured in units of the home value added. Even though we do not explicitly introduce money and the monetary authority into the economy the endogenous risk premium is amongst critical channels that contribute to the practical interrelation between the fiscal and monetary policy. Furthermore, both the endogenous risk premium and the overlapping-generation character of the economy (with redistribution of wealth of died households) limits to some extent the openness of the financial account and allow for an income 
effect of demand-side factors on the relative price of tradables and non-tradables in the sense of Gregorio and Wolf (1994). This is another link between fiscal and monetary policy that is worth investigating.

For the clarity of our exposition we only assume a non-stochastic version of the economy where the only uncertainty pertains to the households' life length. As no money exists here we use the tradable goods (providing both consumption and investment services) as the numeraire.

\section{1 Households}

At each period a generation of a constant size is born. Onwards, each household faces a constant probability of death, $p$, so that the generation size is descending at the rate of $(1-p)$. The usual practice is to normalize the initial size of each generation to $p$ getting the whole population size of 1 and the aggregate quantities can be then interpreted in per-capita terms.

Moreover, the expected life horizon is easily proved $1 / p$ which is a useful guideline for calibration. The reprezentative households setups their optimal program that maximizes the expected utility taking into account the uncertain life horizon:

$$
\sum_{\tau=0}^{\infty}(1-p)^{\tau} \beta^{\tau}\left[U\left(c_{t+\tau}, z_{t+\tau}\right)+V\left(1-n_{t+\tau}\right)\right]
$$

where $p$ denotes the probability of death, $\beta$ is the households' discount factor, $U$ is the instantaneous utility from consumption measured by the index $c, z$ is the reference habit stock in consumption evolving exogenously ("external", "outward-looking", or "catching-up-with-the-Joneses" habit formation), $V$ is the utility from leisure, i.e. $1-n$, and $E$ is the conditional expectations operator. We rely upon the following functional forms for $U$ and $V$ :

$$
\begin{aligned}
& U \equiv c_{t}^{1-\sigma-\phi} z_{t}^{\phi} /(1-\sigma-\phi), \sigma>1, \phi \geq 0 \\
& V \equiv 1-n_{t}
\end{aligned}
$$

First, the habit enters the utility multiplicatively which is both analytically more tractable and more intuitive for balanced-growth steady states than the frequently encountered additive specification. Second, utility from lesiure (or disutility from labor effort) is linear which captures the indivisible-labor effect preannounced in the early paragraph of this section (see Hansen, 1985).

The CES consumption index $c$ is defined over tradable and non-tradable subindices, $c t$ and $c n$, with both of them being CES indeces over consumption of individual types of goods, $\operatorname{ct}(k)$ and $c n(k)$ :

$$
\begin{aligned}
c_{t} & =c t_{t}^{\omega} c n_{t}^{1-\omega} \\
c_{t}^{(\theta-1) / \theta} & =\sum_{k} c t(k)_{t}^{(\theta-1) / \theta} \\
c_{t}^{(\xi-1) / \xi} & =\sum_{k} c n(k)_{t}^{(\xi-1) / \xi}
\end{aligned}
$$

where $\omega, \theta$, and $\xi$ denote respectively the tradables expediture share, the elasticity of substitution amongst individual types of tradables and the one amongst individual types of non-tradables.

The usual budget constraint applies to each period, $t=0,1, \ldots$,

$$
b h_{t+\tau}-\left(1+r_{t-1}\right) /(1-p) b h_{t+\tau-1}=w_{t} n_{t}+\pi t_{t+\tau}+\pi n_{t+\tau}+\pi k_{t+\tau}+t f_{t}-c_{t+\tau} p c_{t+\tau}
$$


where $b h$ is the households' net position in units of tradables, $r$ is the country-specific interest rate, $w$ is the after-tax real wage rate, $\pi t, \pi n$, and $\pi k$ are respectively claims to after-tax net cash flows from tradables producers, non-tradables producers, and capital rental firms, $t f$ is the transfer from government, and $p c$ is the usual aggregate consumption price index (based on the expenditure minimization). The rate of wealth growth is by $1 /(1-p)$ higher then the gross rate of interest due to the insurance-market redistribution of wealth of died households.

Solution to the reprezentative household's optimization gives rise to the following standard first-order conditions

$$
\begin{gathered}
c_{t} \psi_{t}=v_{t}, \\
v_{t}=b h_{t-1}\left(1+r_{t-1}\right) /(1-p)+x_{t}, \\
x_{t}=w_{t} n_{t}\left(1-\eta_{w}\right)+\pi_{t}+(1-p) /\left(1+r_{t}\right) x_{t+1}, \\
\psi_{t}=1+(1-p)(1+\beta)^{-1 /(\sigma+\phi)}\left[\left(1+r_{t}\right)\left(p c_{t} / p c_{t+1}\right)\right]^{1 /(\sigma+\phi)-1}\left(z_{t+1} / z_{t}\right)^{\phi /(\phi+\sigma)} \psi_{t+1}, \\
c t_{t}=\omega c_{t} p c_{t}, \\
c n_{t} p c n_{t}=(1-\omega) c_{t} p c_{t}, \\
c t(k)_{t} / c t_{t}=\left[p c_{t}(k)_{t} / p c t_{t}\right]^{-\theta}, \\
c n(k)_{t} / c n_{t}=\left[p c n(k)_{t} / p c n_{t}\right]^{-\chi}
\end{gathered}
$$

where the current-period consumption as a fraction $\psi$ out of the present value of the household's wealth, $v$, which is the prerequisite for later aggregation across generations; the wealth itself consists of what is usually named "financial wealth", i.e. the first r.h.s. term in (2b), and "human wealth", $x$ (see 2c), expressed as a forward iteration. The law of motion for $\psi$ is rather complex due to two factors (as opposed to the major part of OLG literature): first, the preferences over consumption feature non-unit elasticity of intertemporal substitution, and second, the habit formation is present in the utility. Equations $(2 \mathrm{e})$ through $(2 \mathrm{~h})$ are standard rules guiding intratemporal consumption decision.

\section{2 Producers of Tradables}

The $k$-th tradables producer has a two-factor production technology

$$
y t(k)_{t}=k t(k)_{t-1}^{1-\lambda} \ell t(k)_{t}^{\lambda},
$$

where $k t$ and $\ell t$ denote respectively quantities of physical capital (lagged timing is a convention to express the predetermined character of this input factor) and labor employed in the production. He maximizes the present-valued net cash flow

$$
\sum_{t=0}^{\infty} \rho_{t, t+\tau}\left(1-\eta_{\pi}\right)\left(y t(k)_{t+\tau}\left(1-\eta_{y}\right)-w_{t+\tau} \ell t(k)_{t+\tau}\left(1-\eta_{w}\right)-q t_{t+\tau} k t(k)_{t+\tau-1}\right),
$$

subject to its demand curve (see household's optimization problem)

$$
y t(k)_{t+\tau} / y t_{t+\tau}=\left(p y t(k)_{t+\tau} / p y t_{t+\tau}\right)^{-\theta}
$$


where $q t$ is the rental price of capital, $\eta_{p}$ is the corporate profit tax rate, $\eta_{y}$ is the value added (indirect) tax rate, $\eta_{w}$ is the rate of labor income tax collected at employers, and again yt and pyt without round-bracket indexation stand for respectively aggregate (marketwide) indeces. The pricing kernel $\rho$ is based upon the present shadow value of households' wealth (i.e. present-valued langrange multipliers associated with their budget constraints), in particular

$$
\rho_{t, t+t}= \begin{cases}1, & \text { if } \tau=0, \\ \rho_{t, t+\tau-1} /\left(1+r_{t+\tau-1}\right) & \text { if } \tau \geq 1,\end{cases}
$$

However, this is merely static optimization problem and we end up with the individual markup behavior

$$
\begin{gathered}
\lambda y t(k)_{t}\left(1-\eta_{y}\right)=w_{t} l t(k)_{t}\left(1+\eta_{w}\right) \theta /(\theta-1), \\
(1-\lambda) y t(k)_{t}\left(1-\eta_{y}\right)=q t_{t} k t(k)_{t-1} \theta /(\theta-1)
\end{gathered}
$$

Next, we denote the gross (before-tax) profit

$$
\gamma t(k)_{t} \equiv y t(k)_{t}(1-\eta y)-w_{t} \ell t(k)_{t}\left(1+\eta_{w}\right)-q t_{t} k_{t}
$$

the after-tax net cash flow claimed by households as

$$
\pi t(k)_{t} \equiv\left(1-\eta_{\pi}\right) \gamma t(k)_{t}
$$

\section{3 Producers of Non-tradables}

The optimization problem of the $k$-th non-tradables producer is perfectly analogous to that of tradables up to the technology specification, namely

$$
y n(k)_{t}=a n_{t} \ln (k)_{t}
$$

subject to its demand curve

$$
y n(k)_{t} / y n_{t}=\left(p y n(k)_{t} / p y n_{t}\right)^{-\xi}
$$

where an is the marketwide scale parameter to account for changes in relative productivity between the two sectors. The first order condition is then obviously

$$
\operatorname{pyn}(k)_{t} y n(k)_{t}\left(1-\eta_{y}\right)=w_{t} \ln (k)_{t}\left(1+\eta_{w}\right) \xi /(\xi-1)
$$

or after substitution from the production function

$$
\operatorname{pyn}(k)_{t} a n_{t}\left(1-\eta_{y}\right)=w_{t} \xi /(\xi-1)
$$

The before-tax profit is then

$$
\gamma n(k)_{t}=y n(k)_{t} \operatorname{pyn}(k)_{t}\left(1-\eta_{y}\right)-w_{t} \ell n(k)_{t}\left(1-\eta_{w}\right)
$$

and the claim to the after-tax net cash flow

$$
\pi n(k)_{t} \equiv\left(1-\eta_{p}\right) \gamma n(k)_{t}
$$

\section{4 Capital Rental Firms}

Capital rental firms operate in a competitive market. The reprezentative firm maximizes the present-valued net cash flow 


$$
\sum_{t=0}^{\infty} \rho_{t, t+\tau}\left(q t_{t+\tau} k t_{t+\tau-1}-i t_{t+\tau}\right)
$$

subject to the capital accumulation constraint

$$
k t_{t+\tau}=k t_{t+\tau-1}(1-\delta)+i t_{t+\tau}+J\left(k t_{t+\tau}, k t_{t+\tau-1}\right)
$$

where it is the current-period investment (using tradable goods), $\delta$ is the depreciation rate of physical capital, and $J$ is the capital installation cost schedule (adjusment cost). We think of this cost as a fraction consumed from the previously installed capital, where the fraction is quadratic in the rate of change of capital

$$
J \equiv j\left[\left(k t_{t}-k t_{t-1}\right) / k t_{t-1}\right]^{2} k t_{t-1}
$$

where $j$ is the scale parameter. Notice that zero cost occurs along the stationary steady state (in which there is only the necessary renewal investment).

We perform the optimization with respect to the capital stock, $k t$, plugging the accumulation constraint directly into the production function. The first order condition is then

$$
1+J_{1}\left(k t_{t}, k t_{t-1}\right)=(1-p) /\left(1+r_{t}\right)\left[1+q t_{t+1}-\delta-J_{2}\left(k_{t+1}, k_{t}\right)\right]
$$

which is in effect exactly the Tobin's- $q$ law of motion.

\section{5 The Government}

The government net asset position evolves according to

$$
b g_{t}=\left(1+r_{t-1}\right) b g_{t-1}+\eta_{w} w_{t} \ell_{t}+\eta_{y}\left(y t_{t}+y n_{t} p y n_{t}\right)+\eta_{\pi}\left(\gamma t_{t}+\gamma n_{t}\right)-g n_{t}-t f_{t}
$$

where $\ell_{t} \equiv \ell t_{t}+\ell n_{t}$, and $g$ denotes the government consumption expenditures on non-tradables.

The behavior of tax rates, consumption expenditures, and transfers is subject to various types of fiscal fules and differs across simulations as will be described in the section 3 .

\section{6 Aggregation, Market Clearing, and Solution}

We close the model by aggregating the individual quantities, adding market clearing conditions, and specifying the ad-hoc country risk premium rule. Let's remember that the critical feature of the perpetual-youth kind of models is different rate at which the individual versus aggregate wealth accumulates, namely, after the necessary algebra of aggregating (1) we get the 1.h.s. as

$$
b h_{t}-\left(1+r_{t}\right) b h_{t-1}
$$

Under symmetric equilibrium, the aggregate (economy-wide) behavior coincides with the above first-order conditions and budget constraints where the round-bracket (individual households and individual producers) indexation is dropped. Furthermore, we must impose

$$
y n_{t}=c n_{t}+g n_{t}
$$

For future references we denote the total real output of the home economy

$$
y \equiv y t_{t}+y n_{t} p y n_{t}
$$

and the country's net asset position

$$
b_{t} \equiv b h_{t}+b g_{t}
$$


Last, we capture the foreign investors' attitude towards risk in the following, rather ad-hoc than structural, premium-augmented real interest rate parity

$$
\left(1+r_{t}\right)=\left(1+R_{t}\right)\left(1+u_{t}\right)
$$

where $R$ is the world (reference) real interest rate and $u$ is the endogenous risk premium faced by the home country

$$
\left(1+u_{t}\right)=\left(1-b_{t} / y_{t}\right)^{\varepsilon}, \varepsilon \geq 0
$$

When running the model we first find the stationary steady state and calculate the first-order log-approximation to the local dynamics. The simulations are then computed using the generalized Schur decomposition as proposed by Klein (2000).

\section{7 Calibration of the Model}

We calibrate the model for simulation at annual frequency using behavioral parameters more or less standard to the real business cycle literature. Furthemore, we use the actual (as of 2000) Czech fiscal statistics to set the steady-state effective tax rates. The proportion of corporate profit tax receipts in total fiscal budget along with the observed average labor share of GDP is then also used as a guideline for calibration of average profit rates (and hence markups or elasticities of intratemporal substitutions) of tradables and non-tradables producers.

Table 1 shows the private-sector deep structural parameters; Table 2 checks some model properties implied by this particular calibration; Table 3 provides some background fiscal statistics for the baseline calibration of the government parameters that are found in Table 4. However, these parameters as well as implied ratios (shares of government receipts and expenditures, or proportions of government sector to the whole economy) differ in simulations as the ways of fiscal consolidation vary.

Table 1

Deep Structural Parameters of Private Sector

\begin{tabular}{|l|l|c|}
\hline$p$ & Probability of death & 0.02 \\
\hline$\beta$ & Households' discount factor & 0.97 \\
\hline$\sigma$ & Elasticity of intertemporal subsitution & 1.5 \\
\hline$\phi$ & Weight on habit in consumption & 5.0 \\
\hline$\omega$ & Proportion of tradables in consumption expenditures & 0.5 \\
\hline$\theta$ & Elasticity of substitution amongst tradables & 6.0 \\
\hline$\xi$ & Elasticity of substitution amongst non-tradables & 3.0 \\
\hline$\lambda$ & Labor share in production of tradables & 0.6 \\
\hline$\delta$ & Rate of physical capital depreciation & 0.1 \\
\hline$j$ & Scale parameter at installation cost & 100 \\
\hline$R$ & World real interest rate & 0.03 \\
\hline$\varepsilon$ & Elasticity of risk premium w.r.t. indebtness & 0.1 \\
\hline
\end{tabular}


Table 2

Implied Properties

\begin{tabular}{|l|c|}
\hline Expected life horizon & 50 \\
\hline Weight of lagged consumption in households' decision & 0.43 \\
\hline Markup in tradables & 1.2 \\
\hline Markup in non-tradables & 1.5 \\
\hline
\end{tabular}

Table 3

Basic Czech Fiscal Statistics (as of 2000)

\begin{tabular}{|l|l|}
\hline Effective tax rates & 0.17 \\
\hline Indirect taxes & 0.14 \\
\hline Labor income tax & 0.46 \\
\hline Social contributions & 0.12 \\
\hline Corporate profit tax & \\
\hline Proportions of fiscal receipts & 0.30 \\
\hline Indirect taxes & 0.12 \\
\hline Labor income tax & 0.38 \\
\hline Social contributions & 0.09 \\
\hline Corporate profit tax & 0.11 \\
\hline Other-than-tax receipts & \\
\hline Proportions of fiscal expenditures & 0.42 \\
\hline Consumption & 0.11 \\
\hline Investment & 0.29 \\
\hline Transfers & 0.02 \\
\hline Interest & 0.16 \\
\hline Others & \\
\hline Ratios to GDP & 0.25 \\
\hline Govt. consumption and investment to GDP & 0.14 \\
\hline Transfers to GDP & 0.07 \\
\hline Other expenditures to GDP & \\
\hline
\end{tabular}

Table 4

Parameters of Government Sector

\begin{tabular}{|l|l|l|}
\hline$\eta_{y}$ & Value added tax rate & 0.17 \\
\hline$\eta_{w}$ & Labor income tax & 0.60 \\
\hline$\eta_{\pi}$ & Corporate profit tax & 0.10 \\
\hline$g n p n / y$ & Govt. consumption to real output & 0.32 \\
\hline$t f / y$ & Tranfers to real output & 0.13 \\
\hline
\end{tabular}




\section{Comparative Statics}

We start the description of the effects of different fiscal consolidations by presenting the steady-state effects. The simulated fiscal consolidations are based on the ultimate condition for government debt. The target level for government debt is $10 \%$ of the real output of the home economy. At the start of the simulations we impose a shock that enhances the ratio of the government debt to the real output up to the level of $20 \%$. The government then immediately starts the fiscal consolidation in order to return to the $10 \%$ target level.

As already mentioned above, in order to highlight some specific features of the consolidation we only consider two extreme cases of the consolidation performed via some isolated fiscal instruments. That is why Type 1 consolidation employs only changes in value added tax, even though this is far from being the optimal policy choice; optimal in the sense suggested by Chari and Kehoe (1999). The opposite Type 2 consolidation is based only on changes of government transfers and government consumption. Let's bear in mind that the steady-state properties of the economy under different types of consolidation have no meaning per se. They can only be contrasted and compared to each other.

\section{1 Consolidation through Value Added Tax}

We fix the government parameters at values stated in Table 4, except for the value added tax. This means that the government is allowed to use only the value added tax to meet its target. Next to it we set the government debt target to $10 \%$ of the real output and compute the implied value added tax consistent with this degree of indebtedness in the model steady state. Technically we introduce a fiscal rule in the form

$$
\eta_{y, t}=\eta_{y, t-1}-\alpha_{y}\left(b g_{t} / y_{t}-\text { target }\right), \alpha_{y}>0
$$

where $\eta_{y}$ is the value added tax rate, $b g$ denotes the government net asset position, $y$ is the real output, and target is the target in terms of the degree of government indebtedness.

\section{2 Consolidation through Transfers}

For this consolidation type we fix government parameters at values stated in Table 4, except for the ratio of transfers to the real output. This restriction allows the government to use only the transfers to meet the targeted debt to output ratio. Similarly, as in the previous case we set the ultimate government debt to $10 \%$ of the real output and compute the implied level of transfers consistent with this degree of indebtedness in the model steady state. Again, we introduce a fiscal rule in terms of the instrumental variable

$$
t f_{t} /\left(w_{t} \ell_{t}\right)=t f_{t-1} /\left(w_{t-1} \ell_{t-1}\right)+\alpha_{t f}\left(b g_{t} / y_{t}-\text { target }\right), \alpha_{t f}>0
$$

where $t f$ are the government transfers to households, and $w$ is the labor income of households (so that the ratio of the average transfer to a household over the average labor income is in fact the instrument).

The following Table 5 reports the ultimate steady state values of different variables corresponding with the particular fiscal consolidation type. It is straightforward that the steady state of Type 2 consolidation is characterised by lower level of value added tax rate and lower level of government transfers. Although the proportion of private consumption in real output is almost the same, the higher capital-to-output 
ratio shows that Type 2 consolidation leaves the economy at higher level. It then implies that the steady state level of private consumption is also higher.

Table 5

Steady State Values - Type 1 and Type 2 Consolidations

\begin{tabular}{|l|c|c|}
\hline & $\begin{array}{c}\text { Type 1 } \\
\text { (V.A.Tax) }\end{array}$ & $\begin{array}{c}\text { Type 2 } \\
\text { (Transfers) }\end{array}$ \\
\hline Value added tax & 0.26 & 0.17 \\
\hline Transfers to real output & 0.13 & 0.06 \\
\hline Proportion of value added tax in govt. receipts & 0.56 & 0.44 \\
\hline Relative price of non-tradables in units of tradables & 1.04 & 1.12 \\
\hline Proportion of consumption in real output & 0.62 & 0.61 \\
\hline Capital-to-output ratio in tradable sector & 1.63 & 1.83 \\
\hline Labor in tradable sector to labor in non-tradable sector & 0.44 & 0.45 \\
\hline Total labor to real output & 0.87 & 0.80 \\
\hline
\end{tabular}

\section{Transitory Dynamics}

In this section we examine the transitory dynamics around the steady state under Type 1 and Type 2 consolidation and fiscal rules. The model was calibrated and used at the annual frequency.

\section{1 Consolidation through Value Added Tax}

For the Type 1 simulations we set $\alpha_{y}=1$ in the used fiscal rule. All other taxes are kept fixed as well as the ratio of government consumption to real output and the ratio of transfers to households' labour income. The whole fiscal adjustment is realised through the changes in value added tax rate. Graphs $1-8$ show the dynamic paths around the steady state for the consolidation Type 1. The zero level in all graphs represents the steady state values. Let's keep in mind that the ultimate steady state differs from the initial since the consolidation type has also an impact on steady state values.

Graph 1 shows the sharp increase in the value added tax rate that is accompanied by the decrease in private consumption (Graph 2). The households try to compensate the sharp decrease in consumption by using the debt financing, so we observe the decline in the ratio of private net assets to real output (Graph 3 ). Since the government is not able to move immediately to the target level of debt to real output ratio, we can observe the path of the gradual movement to the target debt to real output level (Graph 4). We can see that the movement of the debt to real output ratio to target level has under this type of consolidation strong cyclical properties. The cyclicality and the overshooting is caused by strong decline in consumption and output after the increase of value added tax rate. It implies lowering of transfers and government consumption since both are assumed to be proportional to household labour income and real output respectively. Facing the dropout in households' labour income and real output, the government is forced to decrease momentarily the go- 
vernment consumption and also the level of transfers (Graph 5 and 6). As a result of dampening the private saving and investment and the rise of the risk premium we observe the increase in real interest rate (Graph 7). The rise of the risk premium is caused by the initial increase of the government debt.

Graph 1

Value Added Tax Rate

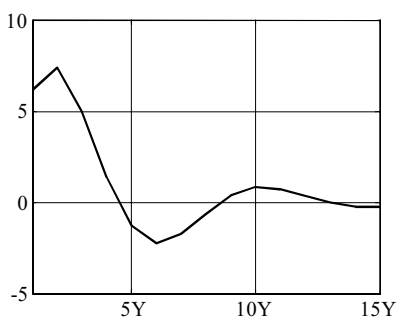

Graph 4

Government Net Assets

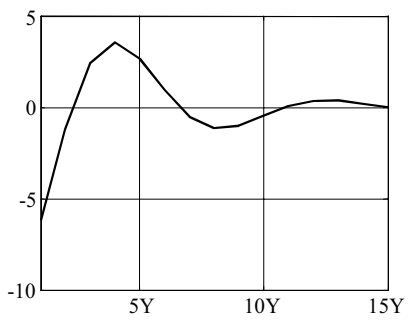

Graph 7

Real Interest Rate

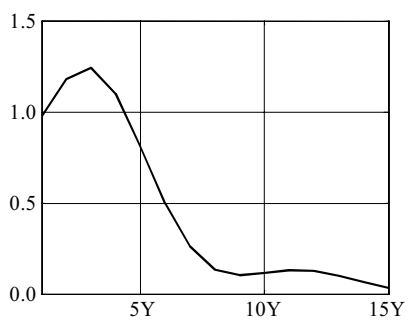

Graph 2

Private Consumption

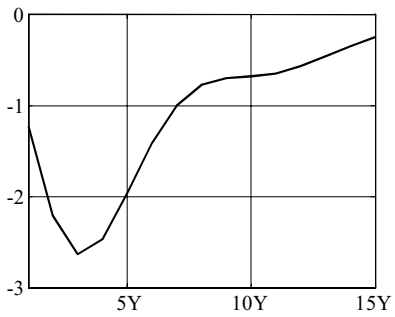

Graph 5

Government Consumption

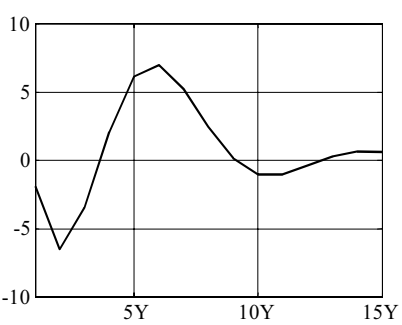

Graph 3

Private Net Assets

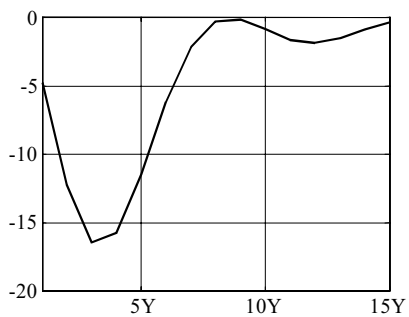

Graph 6

Transfers to Households

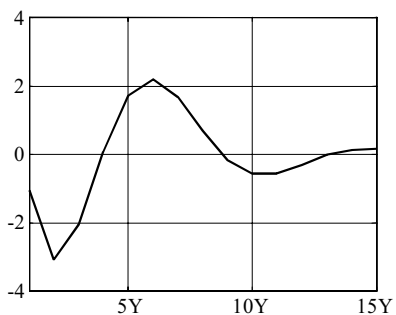

Graph 8

Prices of Non-tradable to Tradable Goods

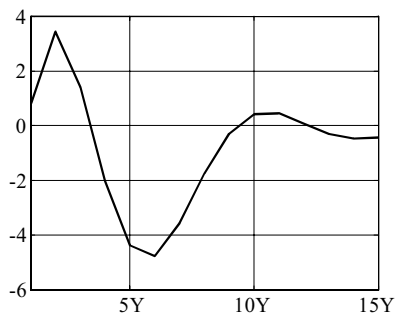

\section{2 Consolidation through Transfers}

The contrasting case of fiscal consolidation (Type 2) is based on changes of government transfers to households. To make the transitory dynamics and the magnitude of fiscal reactions more realistic we accompany the transfer based fiscal rule by another in terms of government consumption

$$
g n_{t} / y_{t}=g n^{S S} / y^{s S}+\alpha_{g n}\left(b g_{t} / y_{t}-\text { target }\right), \alpha_{g n}>0
$$


where gn denotes government purchases of non-tradable goods. So the fiscal authority tries to fulfill its target by changing the level of transfers to households and the level of government consumption. For the Type 2 simulations we set $\alpha_{t f}=1, \alpha_{g n}$ $=1$. All tax rates are kept fixed at levels denoted in Table 4.

Graphs $9-16$ demonstrate the dynamic paths of relevant variables. The ordering of the graphs corresponds with the ordering of graphs of Type 1 consolidation. Only the first Graph 9 depicts the behaviour of total labor instead of value added tax rate since the tax rate is fixed in this case.

As in the previous consolidation type here we also observe the decline in private consumption (Graph 10) accompanied by the decrease of private assets to real output ratio. But the extent of this decrease is substantially lower in comparison to the Type 1 consolidation. This is partly caused by the fact that the consolidation is also accompanied by the decline in government consumption and also by the fact that households react more positively to fiscal consolidation based on cuts in ex-

Graph 9

Labor

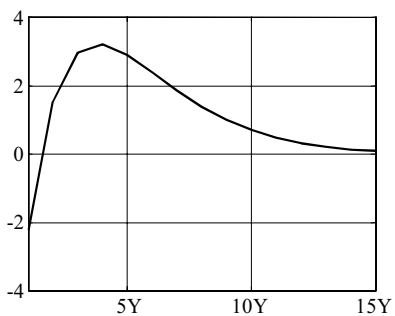

Graph 12

Government Net Assets

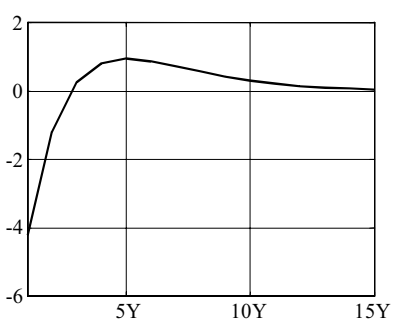

Graph 10

Private Consumption

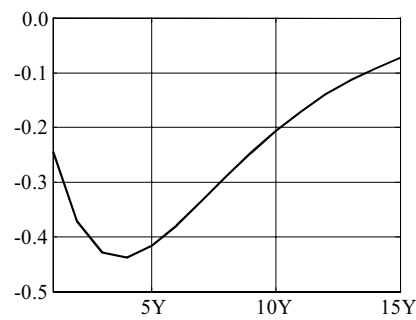

Graph 13

Government Consumption

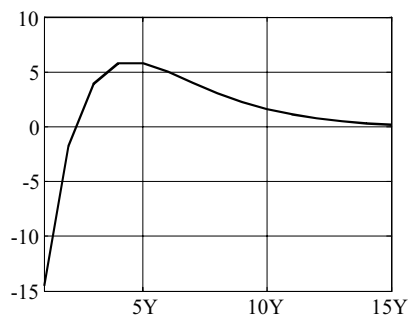

Graph 11

Private Net Assets

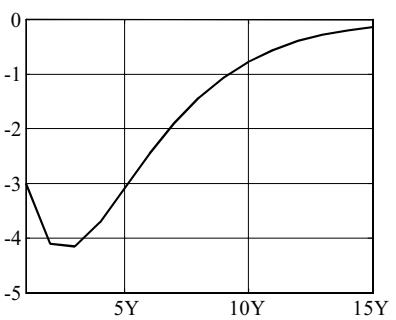

Graph 14

Transfers to Households

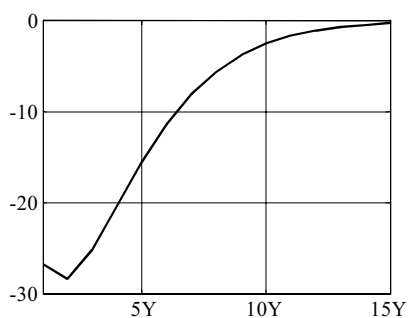

Graph 15

Real Interest Rate

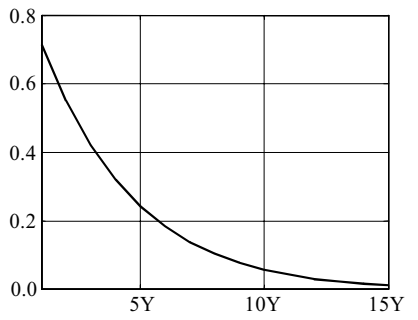

Graph 16

Prices of Non-tradable

to Tradable Goods

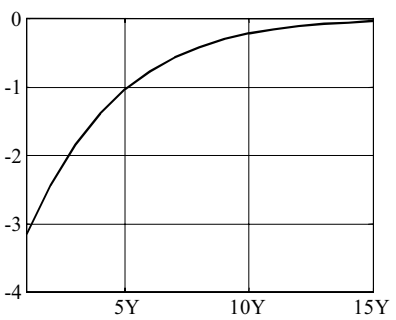


penditures. On the other hand, let's keep in mind that there is also movement in the steady state consumption. The steady state private consumption is getting higher. Thus the Alesina and Perotti conclusion that this kind of consolidation should lead to higher growth of private consumption after approximately first two years of decrease is quite plausible. This result for consumption path holds despite the strong Non-Ricardian equivalency properties of the model.

Graph 12 depicts the adjustment path of government debt to real output ratio. In comparison to the previous example, the movement to target level is quicker, more gradual and the initial deepening of the debt is much lower. The quicker and more gradual return to the target level is caused by the lower initial decrease in private consumption, output and employed labor force, and also by the fact that this decrease is overcome quite smoothly. So the government revenues do not fall so sharply. Finally, the lower initial deepening of the government debt and quicker gradual recovery lead to the lower initial rise of real interest rate and its smooth return to steady state value in comparison to Type 1 consolidation (compare Graphs 15 and 7).

\section{3 Case for Forward-Looking Fiscal Policy?}

It is common practice to use forward-looking monetary policy rule in models of monetary cycles. Following this practice we run an alternative simulation with value added tax based fiscal rule, but augmented with a forward-looking element borrowed from the monetary policy theory

$$
\eta_{y, t}=\eta_{y, t-1}-\alpha_{y}\left(b g_{t+2} / y_{t+2}-\text { target }\right), \alpha_{t f}>0
$$

where $\eta_{y}$ is the value added tax rate, $b g$ denotes the government net asset position, $y$ is the real output, and target is the target in terms of the degree of government indebtedness. In comparison to the Type 1 consolidation, here the fiscal au-

Graph 17

Value Added Tax Rate

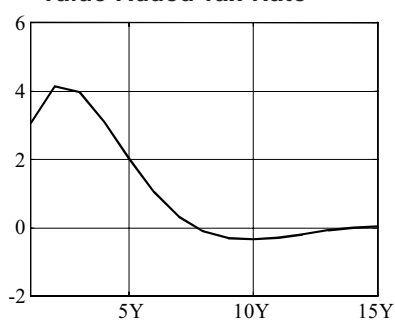

Graph 20

Government Net Assets

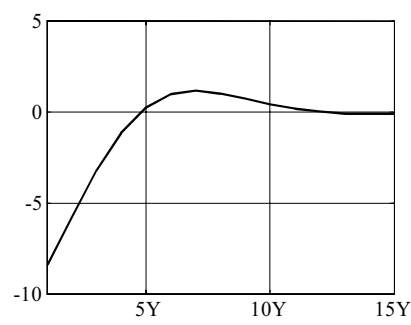

Graph 18

Private Consumption

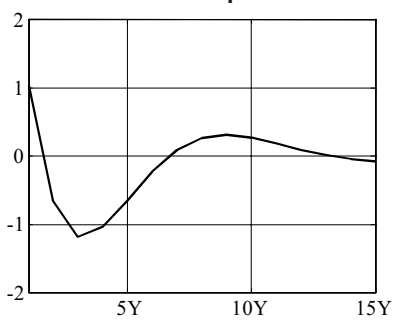

Graph 21

Government Consumption

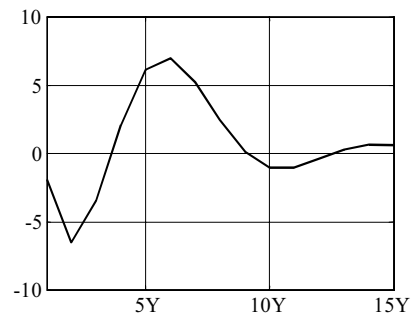

Graph 19

Private Net Assets

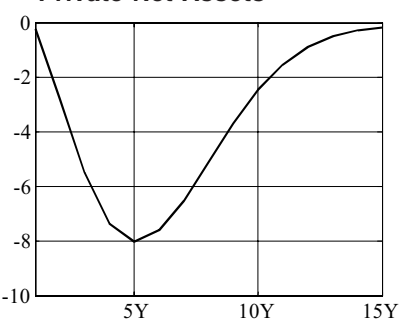

Graph 22

Transfers to Households

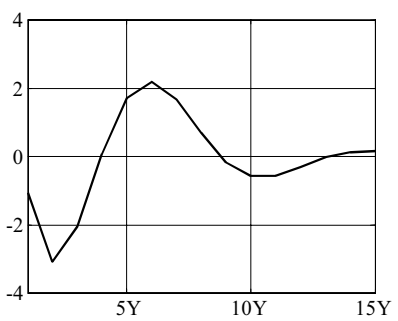


Graph 23

Real Interest Rate

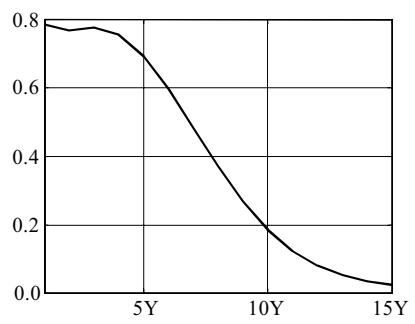

Graph 24

Prices of Non-tradable

to Tradable Goods

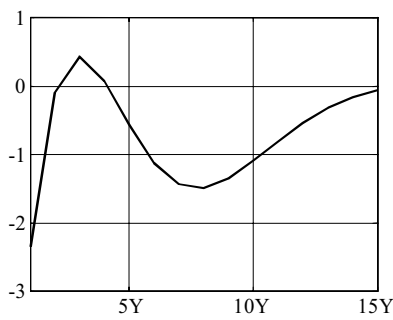

thority does not take into account the actual ratio of government net asset position to the real output, but this variable two years ahead. The forward looking element incorporated in the fiscal rule leads to much smoother reaction of the economy to the fiscal consolidation with no excess cyclicality of particular variables. The graphs $(17-24)$ depict the results of this kind of simulation.

\section{Interaction with Monetary Policy}

To consider the interaction with monetary policy, it is necessary to take into account the movement of real interest rate and the relative price of non-tradables to tradables. From the monetary policy point of view we can distinguish between the ultimate steady state differences and differences in the transitory dynamics.

Considering firstly the steady state properties and using the Table 5 we can conclude that the level of real interest rate is lower after Type 2 consolidation than after Type 1 consolidation, as the capital to output ratio is higher. On the other hand, the price level is higher since the relative price of non-tradables to tradables is higher. Remember that the price of tradables is equal to one. It implies that the monetary policy authority should be prepared to lower the relevant interest rate as the real interest rate declines in order to hold the same level of the monetary conditions; even though it will face the higher growth of the price level.

Secondly, comparing the dynamic paths we can conclude that immediately after consolidation there is a rise in real interest rate and risk premium as the government net assets position gets worse and also the private savings decline. We observe that the rise of real interest rate after the Type 2 consolidation is lower in comparison to Type 1 consolidation. It means that the consolidation that decreases the government consumption and transfers to households has lower negative effects on the economy as a whole. The appropriate reaction of the monetary policy must then also differ with the particular type of fiscal consolidation. The gradual decline of the real interest rate should be accompanied by the slowdown of monetary policy relevant interest rates, as already mentioned above. The decrease of interest rates in the economy is possible only when the fiscal consolidation causes reduction of the risk premium or the increase of the capital stock level.

Other important effect is the impact of fiscal consolidation on transitory dynamics of the changes in the relative price of non-tradables to tradables (Ballassa-Samuelson effect). Comparing Graphs 8, 16 and 24 we can see that the impacts on the relative price of non-tradables to tradables differ substantially. After Type 1 consolidation there is primary rise of the relative price of non-tradables to tradables. It means that the Ballasa-Samuelson effect is initially strengthened. Then after approximately three years the relative price of non-tradables to tradables falls and the 
Ballasa-Samuelson effect is weakened. The strengthening and weakening of the Ballasa-Samuelson effect has direct impact on the speed of the equilibrium real exchange rate appreciation and thereby on monetary policy. In comparison, after Type 2 consolidation we observe immediate decline of the relative price of non-tradables to tradables, weakening of the Ballasa-Samuelson effect, and reduction of the speed of the equilibrium real exchange rate appreciation. These effects of course require different monetary policy measures.

\section{Conclusion}

This paper examined two different scenarios of fiscal consolidation. One was based on the value added tax changes, the other on changes in the government transfers and consumption. The simple dynamic general equilibrium model was used to examine the implications of those different consolidation strategies on the economy. The used model had been calibrated for the case of the Czech economy.

The comparison of all types of simulated fiscal consolidation scenarios showed that their effects differ substantially. It holds for both the effects on the ultimate steady state properties as well as on the dynamics around the steady states. The consolidation based on the reduction of the expenditure side has lower negative effect on the initial private consumption decline. The recovery of the economy and transition from initial to ultimate steady state is faster in this case and the ultimate steady state demonstrates better properties: the higher capital to output ratio and lower tax rates. These results hold despite the fact that the used model does not stress the Ricardian equivalence properties.

Despite the better theoretical effects of fiscal consolidation based on the expenditure side, the actual fiscal consolidation is more likely to be based on the revenue side of public budgets, later followed by the reduction of government consumption and transfers. Our simulation showed that the forward-looking approach can reduce the negative effects of revenue based consolidation quite a lot.

Other important result is the appropriate reaction of the monetary policy. We have shown that mainly two effects of the fiscal consolidation influence the monetary policy reaction. First, it is the effect of fiscal consolidation on the real interest rate and risk premium movement. Second, it is the effect on the changes in the relative price of non-tradables to tradables, i.e. the extent of the Ballassa-Samuelson effect, and thereby on the speed of equilibrium exchange rate appreciation.

In general, the used model enables us to evaluate different types of fiscal consolidation scenarios and provides results that are not in contradiction with the empirical evidence. However useful, our model still provides only initial insight into the modeling of the effects of fiscal consolidation. The credible evaluation of the impacts of really announced fiscal consolidation requires further research and rebuilding the used model.

References

Alesina, A., Perotti, R. (1996), "Fiscal Adjustments in OECD Countries: Composition and Macroeconomic Effects." Cambridge, MA, NBER Working Paper Series, 5730.

Blanchard, O. J. (1985), "Debt, Deficits, and Finite Horizons." Journal of Political Economy, 93, pp. 223-247.

Chari, V. V., Kehoe, P. J. (1999), "Optimal Fiscal and Monetary Policy." Cambridge, MA, NBER Working Paper Series, 6891. 
Faruqee, H., Laxton, D. (2000), "Life-cycles, Dynasties, Saving: Implication for Closed and Small Open Economies." Washington, IMF, Working Paper 00/126.

Gregorio, J. D., Wolf, H. C. (1994), "Terms of Trade, Productivity, and the Real Exchange Rate." Cambridge, MA, NBER Working Paper Series, 4807.

Hansen, G. (1985), "Indivisible Labor and the Business Cycle." Journal of Monetary Economics, 16, pp. 309-427.

Evans, P. (1991), "Is Ricardian Equivalence a Good Approximation?" Economic Inquiry, pp. 626-644. Klein, P. (2000), "Using the Generalized Schur Form to Solve a Multivariate Rational Expectations Model." Journal of Economic Dynamics and Control, 24, pp. 1405-1423.

Kopits, G. (2001), "Fiscal Rules: Useful Policy Framework or Unnecessary Ornament?" Washington, IMF, IMP Working Paper 01/145.

Sutherland, A. (1995), "Fiscal Crisis and Agreggate Demand: Can High Public Debt Reverse the Effect of Fiscal Policy?" London, CEPR, Working Paper.

Yaari, M. E. (1965), "Uncertain Lifetime, Life Insurance, and the Theory of the Consumer." Review of Economic Studies, 32, pp. 137-150. 